\author{
Marquette University \\ e-Publications@Marquette
}

School of Dentistry Faculty Research and

Publications

Dentistry, School of

7-2011

\title{
Galvanic Corrosion between Various Combinations of Orthodontic Brackets and Archwires
}

Arash Bakhtari

T. Gerard Bradley

Marquette University, thomas.bradley@marquette.edu

William K. Lobb

Marquette University, william.lobb@marquette.edu

David W. Berzins

Marquette University, david.berzins@marquette.edu

Follow this and additional works at: https://epublications.marquette.edu/dentistry_fac

Part of the Dentistry Commons

\section{Recommended Citation}

Bakhtari, Arash; Bradley, T. Gerard; Lobb, William K.; and Berzins, David W., "Galvanic Corrosion between Various Combinations of Orthodontic Brackets and Archwires" (2011). School of Dentistry Faculty Research and Publications. 40.

https://epublications.marquette.edu/dentistry_fac/40 
Marquette University

e-Publications@Marquette

\title{
Dentistry Faculty Research and Publications/School of Dentistry
}

This paper is NOT THE PUBLISHED VERSION; but the author's final, peer-reviewed manuscript. The published version may be accessed by following the link in the citation below.

American Journal of Orthodontics and Dentofacial Orthopedics, Vol. 140, No. 1 (July 2011): 25-31. DOI. This article is (c) Elsevier and permission has been granted for this version to appear in $\underline{\mathrm{e}-}$ Publications@Marquette. Elsevier does not grant permission for this article to be further copied/distributed or hosted elsewhere without the express permission from Elsevier.

\section{Galvanic Corrosion Between Various Combinations of Orthodontic Brackets and Archwires}

\author{
Arash Bakhtari \\ Private practice, Los Angeles, Calif \\ Thomas Gerard Bradley \\ Department of Developmental Sciences, School of Dentistry, Marquette University, Milwaukee, Wis \\ William K. Lobb \\ School of Dentistry, Marquette University, Milwaukee, Wis \\ David W. Berzins \\ Department of General Dental Sciences, School of Dentistry, Marquette University, Milwaukee, Wis
}




\section{Abstract \\ Introduction}

The purpose of this study was to compare galvanic currents generated by different combinations of commonly used brackets and archwires.

\section{Methods}

As-received stainless steel, nickel-titanium, and beta-titanium wires were coupled to stainless steel and titanium brackets in an artificial saliva medium. The galvanic current and amount of charge transferred for each pair were monitored with a zero resistance ammeter for 10 hours.

\section{Results}

Two-way analysis of variance (ANOVA) showed a significant difference in charge and galvanic currents when factored for type of bracket $(P<0.001)$, but no significant difference between them when factored by type of wire $(P>0.05)$. Specifically, a brazed stainless steel bracket was significantly greater in charge transferred and 10 -hour galvanic current than metal injection molded stainless steel and titanium brackets $(P<0.001)$, which were not different from each other $(P>0.05)$.

\section{Conclusions}

The method of bracket manufacturing might be of equal or more relevance to galvanic corrosion susceptibility than bracket composition.

Technologic advances in wire selection and bracket design have improved treatment efficiency and allowed longer intervals between appliance adjustments. This implies that wires will remain in the mouth for a correspondingly longer time, where they are subject to electrochemical reactions, mechanical forces of mastication, and generalized wear. ${ }^{1}$ These various phenomena can cause different forms of corrosion, an electrochemical process that results in the loss of the essential properties of a metal. ${ }^{2}$ Several types of corrosion can take place through 1 of 2 mechanisms. Metal ions can be deposited directly into the saliva, or the protective surface film on the metal can progressively dissolve. ${ }^{2}$ Galvanic corrosion refers to the electrochemical reactions that occur when 2 different metals, immersed in the same solution, are electrically coupled to each other. ${ }^{3}$ When this happens, both metals are polarized, with 1 metal generally becoming a cathode and the other an anode. 2, 3 Compared with its uncoupled rate, the anode experiences an increased corrosion rate, whereas the corrosion rate of the cathode decreases. ${ }^{3}$

Most orthodontic materials are metallic. For example, bands, brackets, facebows, archwires, many types of retainers, and other adjunctive appliances and devices are made of different metals and, therefore, are subject to galvanic and other types of corrosion. Not surprisingly, several studies have observed corrosion on the surface of various orthodontic appliances.4, 5, 6 Most research on corrosion has involved the measurement of ion release, with nickel as the major focus of attention,7, 8, 9, 10, 11 or the corrosion properties of individual materials.12, 13, 14, 15 Fewer studies have investigated galvanic corrosion with various combinations of brackets and wires.16, 17, 18, 19, 20

There are several consequences of corrosion in orthodontics. It has been stated that corrosion is perhaps the single most relevant property of a casting alloy to its biologic safety, since the release of metal ions-ie, corrosion-is a necessary condition for an adverse biologic reaction. ${ }^{21}$ This is most likely true for orthodontic alloys as well. Corrosion of orthodontic alloys will result in the release of the respective metal constituents. In terms of nickel release, it appears that orthodontic treatment does not induce nickel sensitivity in patients 
unless they have a history of cutaneous piercings or of allergic reactions.22, 23 Still, for patients in these categories, and it was estimated that $\mathbf{4 0 0 0}$ orthodontics patients per year develop nickel (or chromium) sensitivity in North America, minimizing elemental release should be a goal in materials development by manufacturers and in material selection by clinicians. ${ }^{24}$ Among other consequences of corrosion, it has been proposed to be among the factors associated with clinical wire fracture ${ }^{25}$ and it increases the surface roughness of the metal, resulting in increased friction. ${ }^{26}$ With these considerations, the purpose of this study was to focus specifically on galvanic current by using different combinations of brackets and archwires that are commonly used in most orthodontic practices.

\section{Material and methods}

Three compositional types of wires and brackets, respectively, were the subject of this research. All similar specimens were from the same batch number and tested in "as-received" condition from the manufacturers. The brackets consisted of a brazed stainless steel bracket (Orthos, Ormco, Glendora, Calif), an injection-molded stainless steel bracket (Equilibrium 2, Dentaurum, Ispringen, Germany), and an injection-molded titanium bracket (Equilibrium Ti, Dentaurum). All 3 types were maxillary central incisor brackets. The wires were composed of stainless steel (Tru-Arch, Ormco), nickel-titanium (NiTi, Ormco), and beta-titanium (TMA, Ormco), each with a diameter of 0.016 in.

All wires were sectioned at the midline marker, and each half arch was placed in a 3.8-cm long polyvinyl chloride pipe and embedded in acrylic (Sampl-Kwick, Buehler, Lake Bluff, III). The ends of the wire extended out of the acrylic, with 1 end to be used for connection to the electrochemical measuring equipment and the other submerged in solution. The submerged end was painted with nail polish to expose only $9 \mathrm{~mm}$ of wire, simulating the average width of a maxillary central incisor. The brackets were individually connected to a $15.2-\mathrm{cm}$ long strand of insulated copper wire, with 1 end flattened to provide a broader contact area. This end was secured to the pad of each bracket with sticky wax, and the wax covered the entire pad to isolate the face of the brackets. The remaining exposed copper wire was insulated with nail polish, and the electrical continuity of the connection was ensured with a multi-meter. The solution used in this study was aerated phosphate buffered saline solution $(\mathrm{pH}=7.4)$ at room temperature $\left(21^{\circ} \mathrm{C} \pm 1^{\circ} \mathrm{C}\right)$. The phosphate buffered saline solution (Fisher Scientific, Houston, Tex) had the following concentration: $137 \mathrm{mmol} / \mathrm{L}$ of sodium chloride, $2.7 \mathrm{mmol} / \mathrm{L}$ of potassium chloride, and $10 \mathrm{mmol} / \mathrm{L}$ phosphate ion and has been used in previous orthodontic wire-corrosion research. ${ }^{27}$

Electrochemical measurements were made with a potentiostat (Gamry Instruments, Warminster, Pa) connected to a desktop computer. The study was divided into 2 phases. In phase I, standard corrosion parameters for each bracket and wire type were measured individually. The electrochemical cell consisted of a saturated calomel reference electrode and a graphite counter electrode. The following protocol was used.

1. The open circuit potential (OCP) was monitored for 10 hours. This time was chosen to be consistent with testing in phase II.

2. A potentiodynamic scan was conducted at $5 \mathrm{mV}$ per second from $300 \mathrm{mV}$ below to $700 \mathrm{mV}$ above each specimen's OCP.

The corrosion current was calculated from the generated data. Four specimens of each bracket and wire type were prepared and tested, with fresh solution used each time.

Phase II was the main focus of this research and involved measuring the galvanic current between each possible combination of bracket and wire. The potentiostat was set up as a zero resistance ammeter, which electrically couples the 2 metals of interest and measures the current flowing between them. To determine the proper electrical connection for each bracket-wire pair, the OCP data from phase I were used to assign the cathode 
(counter-electrode lead) to the more electropositive metal and the anode (working electrode) to the more electronegative metal. The reference electrode for phase II was also a saturated calomel electrode. The galvanic current of the couple was monitored for 10 hours. Ten hours was chosen based on a pilot study that showed that galvanic current plateaus after a few hours. This time is also consistent with other dental galvanic current research. ${ }^{28}$ The total charge was calculated by integrating the area under the current vs time curve. Each combination was tested 4 times with new specimens each time.

\section{Statistical analysis}

Current and charge data were not normalized for surface area as is the conventional practice. This was done primarily because measuring the current flowing between a single bracket and a corresponding segment of wire was desired. Additionally, although the wires were standardized to a specific size, standardization of bracket area is not feasible, and measuring the surface area of the brackets is difficult. The measured and calculated corrosion parameters in phase I were subject to 1-way analysis of variance (ANOVA) followed by the Tukey posthoc test when indicated (SPSS, Chicago, III). Two-way ANOVA and the Tukey post-hoc tests were used for phase II data, with type of wire and bracket as factors. The significance level was set at $\alpha=0.05$.

\section{Results}

The means and standard deviations for the OCP at 10 hours and corrosion current for each type of wire and bracket measured in phase I are shown in Table I. The OCP of the stainless steel wire was significantly greater than all other materials tested $(P<0.05)$. There were no significant differences between the other 5 materials $(P>0.05)$. Potentiodynamic curves of each wire and bracket are shown in Figure 1 . With regard to corrosion current, the stainless steel brackets (Equilibrium 2 and Orthos) had significantly higher values than did all other materials $(P<0.05)$. There were no significant differences between the remaining 4 materials with respect to corrosion current $(P>0.05)$.

Table I. Open circuit potential (OCP) and corrosion current of the materials*

\begin{tabular}{|l|l|l|}
\hline Material & OCP at 10 hours (mV vs SCE) & Corrosion current (nA) \\
\hline Wires & & \\
\hline NiTi & $-41 \pm 21$ & $4.0 \pm 0.9$ \\
\hline Beta-titanium & $-37 \pm 26$ & $6.4 \pm 3.3$ \\
\hline Stainless steel & $170 \pm 49$ & $2.9 \pm 0.3$ \\
\hline Brackets & & \\
\hline Equilibrium Ti & $-58 \pm 27$ & $31.3 \pm 30.3$ \\
\hline Equilibrium 2 & $-24 \pm 36$ & $74.6 \pm 17.4$ \\
\hline Orthos & $-25 \pm 22$ & $92.4 \pm 15.2$ \\
\hline
\end{tabular}

SCE, Saturated calomel electrode.

*The OCP of the stainless steel wire was significantly greater $(P<0.05)$ than all other materials. The corrosion currents of the stainless steel brackets (Equilibrium 2 and Orthos) were significantly greater $(P<0.05)$ than all other materials. 


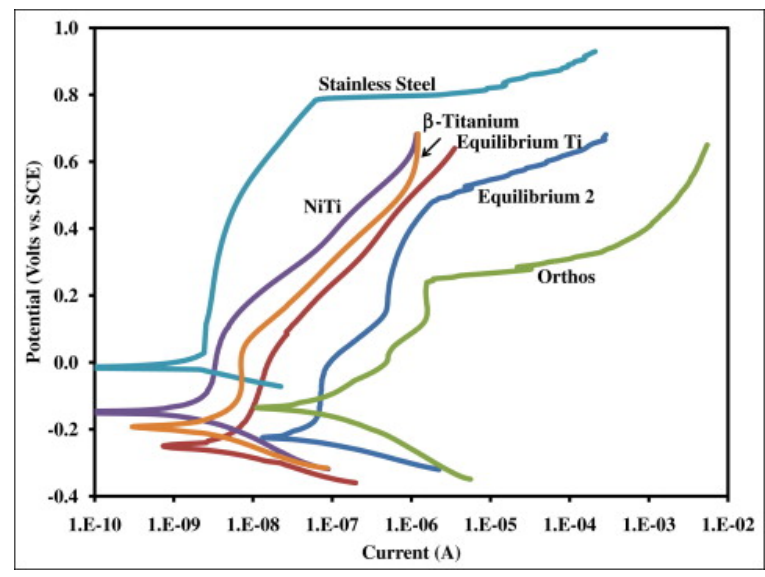

Fig 1. Potentiodynamic curves for the 3 wires and 3 brackets.

In phase II of the study, the galvanic current between each possible combination of wire and bracket was measured for 10 hours. Typical initial segments of current vs time for stainless steel individually coupled to the 3 brackets are shown in Figure 2. The galvanic corrosion was greatest upon immersion in the electrolyte and then decreased over time. The other combinations had similar curves but are not shown for clarity. The means and standard deviations of calculated charge and galvanic current measured at 10 hours for each combination of wire and bracket are shown in Table II. Two-way ANOVA showed a significant difference in charge and galvanic current when factored for type of bracket $(P<0.001)$. Post-hoc Tukey tests subsequently showed a significant difference $(P<0.001)$ between galvanic couples with the Orthos brackets vs couples with either Equilibrium Ti or Equilibrium 2 brackets. There was no significant difference between galvanic couples when the brackets were Equilibrium Ti or Equilibrium 2 ( $P=0.97$ for charge, $P=0.96$ for galvanic current). With regard to the 3 wires (beta-titanium, nickel-titanium, and stainless steel), there were no significant differences between them when factored by type ( $P=0.14$ for charge, $P=0.68$ for galvanic current). Additionally, there was no significant interaction between wire and bracket for either measure $(P>0.05)$. Figure 3 shows a comparison of galvanic currents measured from hours 8 to 10 for all wire-bracket couples. In general, the galvanic currents when the wires were coupled with the Orthos bracket were much greater than when the wires were coupled with the other 2 brackets.

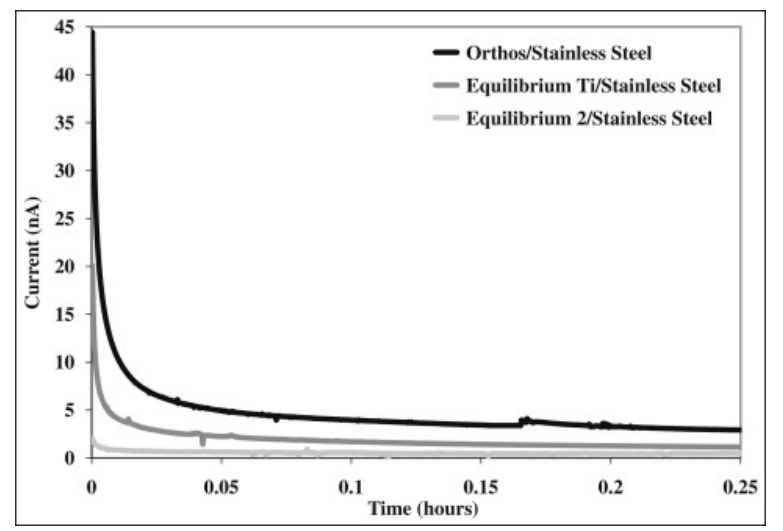

Fig 2. Typical initial segment of galvanic current vs time curves for 3 wire-bracket combinations.

Table II. Charge and current of each wire and bracket combination*

\begin{tabular}{|l|l|l|l|}
\hline Combination & Charge $(\mu \mathrm{C})$ & Galvanic current at 10 hours $(\mathrm{pA})$ \\
\hline
\end{tabular}




\begin{tabular}{|l|l|l|l|}
\hline Wire & Bracket & & \\
\hline Beta-titanium & Equilibrium Ti & $3.6 \pm 3.0$ & $144 \pm 202$ \\
\hline Beta-titanium & Equilibrium 2 & $7.9 \pm 4.6$ & $163 \pm 174$ \\
\hline Beta-titanium & Orthos & $37.9 \pm 25.0$ & $1112 \pm 680$ \\
\hline NiTi & Equilibrium Ti & $3.4 \pm 3.3$ & $120 \pm 177$ \\
\hline NiTi & Equilibrium 2 & $6.2 \pm 4.6$ & $267 \pm 477$ \\
\hline NiTi & Orthos & $18.4 \pm 13.5$ & $625 \pm 567$ \\
\hline Stainless steel & Equilibrium Ti & $11.3 \pm 3.6$ & $226 \pm 96$ \\
\hline Stainless steel & Equilibrium 2 & $7.7 \pm 6.5$ & $192 \pm 82$ \\
\hline Stainless steel & Orthos & $38.8 \pm 20.6$ & $955 \pm 653$ \\
\hline
\end{tabular}

$*$ Orthos brackets were significantly different $(P<0.001)$ from Equilibrium Ti and Equilibrium 2 brackets. There were no significant differences $(P>0.05)$ between Equilibrium Ti and Equilibrium 2 brackets. There were no significant differences between the 3 types of wires $(P>0.05)$.

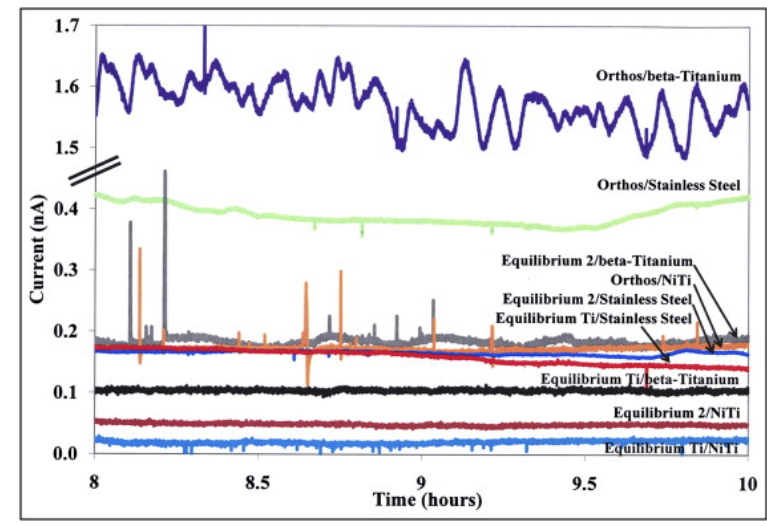

Fig 3. Comparison of galvanic currents measured from hours 8 to 10 for all wire-bracket combinations. Note the break in the $y$-axis scale.

\section{Discussion}

In phase I, interesting findings were observed with respect to OCP and corrosion current. Five of the 6 materials tested possessed statistically similar OCP values in phosphate buffered saline solution. Although the wires and brackets had different compositions, this finding might be due to the passivating oxide films that form on stainless steel and titanium. ${ }^{29}$ With regard to corrosion current, however, both types of stainless steel brackets showed significantly higher values than all other materials. The increased corrosion current might be the result of greater surface areas of the brackets compared with the wires. As mentioned previously, the data were not normalized for surface area because it was desired to replicate the situation with what one would find clinically for a single tooth. Thus, 1 bracket with all surface exposed except the adhesive base was tested, as was a proportionate length of wire. Measurement of the exact surface area of the facial side of the brackets is problematic, but, since all were maxillary central incisor brackets, their surface areas were comparable. By using this protocol, even the lowest mean bracket corrosion current (Equilibrium Ti) was still nearly 1 order of magnitude greater than any of the wires tested. For the brackets, the Equilibrium Ti bracket exhibited 
significantly less corrosion current than the stainless steel brackets, but there were no differences between the 3 wires.

Phase II results suggest that, in the couples formed by the archwires and brackets, the latter might have a more important contribution to the total galvanic current generated, since there were significant differences between galvanic current among the 3 brackets tested but not among the 3 wires. Galvanic currents and charge with the Orthos bracket were significantly higher than those obtained with the Equilibrium 2 or Equilibrium Ti brackets. A previous study confirmed that Orthos brackets are machine milled, with a gold-based brazing alloy joining the base and wing components. ${ }^{30}$ The brazing alloy consisted mainly of gold (74\%), a highly noble element with good resistance to corrosion, alloyed with nearly $12 \%$ nickel and trace amounts of iron, chromium, and manganese. Furthermore, the base and wing were different types of stainless steel. The presence of dissimilar metal component compositions in a single bracket would create a galvanic cell forming on the bracket itself. Further intensification of this effect is probable when coupled to a wire of a different composition. Galvanic corrosion is sensitive to the relative areas of the anode and the cathode. ${ }^{31}$ Although the OCP of the Orthos bracket was similar to that of the NiTi and beta-titanium wires, its measured OCP would reflect the overall potential of the bracket as a whole according to the mixed potential theory. ${ }^{31}$ Distinct compositional areas (base, wing, brazing joint) have different potentials. Therefore, a separate area or component of the Orthos bracket might be the most anodic area of the couple. On a relative scale, a small anode and a large cathode intensify the galvanic current at the anode. This scenario is consistent with the increased galvanic current associated with the Orthos bracket.

In contrast, both the Equilibrium 2 and Equilibrium Ti brackets are manufactured by metal injection molding (MIM). A description of the MIM process and its strengths and weaknesses are described in detail elsewhere, but, because MIM brackets are constructed as a single piece of metal, they would not be as prone to the effects mentioned above when coupled with a wire with similar potential values. ${ }^{32}$ The MIM stainless steel brackets of single composition possessed significantly lower galvanic current values than the multi-component, brazed brackets. In terms of chemical composition by weight percentage, Equilibrium 2 stainless steel brackets are reported to contain mainly iron, up to $19 \%$ chromium, $12.5 \%$ to $15 \%$ nickel, and smaller amounts of silicon, manganese, copper, and sulfur. ${ }^{33}$ Interestingly, although the Equilibrium Ti bracket is over $99 \%$ titanium by weight, it did not differ significantly from the Equilibrium 2 bracket with respect to galvanic charge and current. ${ }^{33}$ Perhaps the resistance to galvanic corrosion afforded to the latter by the MIM process is enough to render it statistically insignificant compared with the titanium-based bracket, despite the mentioned superior corrosion resistance of titanium. ${ }^{34}$ Further work would be beneficial in making a more comprehensive explanation.

Several studies have investigated galvanic corrosion between brackets and wires, but this report substantially differs from those in terms of materials and couples tested and methodology.16, 17, 18, 19, 20 lijima et $\mathrm{al}^{17}$ evaluated disks of stainless steel and titanium bracket materials coupled to disks of stainless steel, nickeltitanium, beta-titanium, or cobalt-chromium-nickel wire materials. Although the material composition matched that of commercial orthodontic bracket and wire end products, the disks differed in terms of materialprocessing history (level of cold working, heat treatment, and so on), which has an effect on properties, since residual stresses associated with manufacturing affect corrosion and account for variations between similar materials. ${ }^{15} \mathrm{~A}$ few studies examined only couples between the wing portion of a bracket and a wire, neglecting the influence of the base and the brazing alloy, if present, depending on the brackets' method of fabrication.18, 19 In the clinical situation, the entire bracket, with the exception of the adhesive bonding side of the base, will be exposed as was the case in our study. In terms of methodology, some studies evaluated surface condition ${ }^{16}$ and the potential difference between the bracket wing and wire.18, 19 Although these methods yielded important information, monitoring galvanic current provides more relevance because it quantifies the 
extent of corrosion and is an indirect measure of elemental release, since the flow of electrons (ie, current) corresponds to the release of metal into the solution. ${ }^{21}$ Still, a weakness in measuring only galvanic current is that the identity and quantity of the specific ions released are not known.

The clinical implications of these findings relate to issues of biocompatibility as a result of ion release from galvanic corrosion. Nickel in particular is a cause of concern because of its reported ability to induce allergic contact dermatitis in patients with previous cutaneous piercings or a history of allergy, as stated earlier.22, 23 These results suggest that, because of their decreased susceptibility to galvanic corrosion, MIM stainless steel brackets might release less nickel than brazed stainless steel brackets. Further study to measure the extent of nickel and other ions released with these wire-bracket couples would be beneficial. Based on the observation that the galvanic current is greatest when the wire and brackets are first coupled and then decreases over time, ion release would be expected to be greatest shortly after archwire placement. Interestingly, the greatest nickel concentration in patients' saliva occurs after bracket and wire placement. ${ }^{35}$

Many electrolytes have been used in dental-materials corrosion research with little consensus and limited ability to replicate the characteristics of saliva and other fluids and conditions observed in the oral environment. Thus, the results here should be interpreted with caution. For instance, Schiff et al ${ }^{20}$ showed that anodic and cathodic rankings of orthodontic alloys might be different in fluoride-containing mouthwashes compared with artificial saliva. Nevertheless, since the galvanic current for the brazed bracket couples ranged from 2.3 to 7.7 times the galvanic current of comparable bracket-wire couples, similar conclusions can be expected in other artificial salivas and electrolytes. Additionally, the results were obtained from in-vitro conditions. Eliades and Athanasiou ${ }^{36}$ described several factors that limit the applicability of in-vitro results to the clinical realm, including the lack of intraoral flora and plaque, the use of nonagitated storage solutions, and the absence of the simulation of ligation.

\section{Conclusions}

1. Galvanic current and charge of couples did not significantly differ by wire type: beta-titanium, nickeltitanium, and stainless steel.

2. The galvanic current and charge of couples consisting of Orthos brackets, which are milled with 2 components brazed together, were significantly higher than the galvanic currents with Equilibrium 2 and Equilibrium Ti brackets, which are MIM brackets.

3. There was no significant difference between galvanic couples when the brackets were Equilibrium Ti or Equilibrium 2.

4. These results indicate that the method of bracket manufacturing might have equal or greater relevance to galvanic corrosion susceptibility than bracket composition. Specifically, the brazed bracket coupled with wires exhibited greater galvanic corrosion than did the MIM brackets.

We thank Ormco and Dentaurum for the generous supply of wires and brackets used in this study.

\section{References}

1 J. Karov, I. Hinberg. Galvanic corrosion of selected dental alloys. J Oral Rehabil, 28 (2001), pp. 212-219

2 J.A. von Fraunhofer. Corrosion of orthodontic devices. Semin Orthod, 3 (1997), pp. 198-205

3 R.W. Revie. Uhlig's corrosion handbook. (2nd ed.), Wiley, New York (2000)

4 R.P. Kusy. Types of corrosion in removable appliances: annotated cases and preventative measures. Clin Orthod Res, 3 (2000), pp. 230-239 
5 E. Petoumeno, M. Kislyuk, H. Hoederath, L. Keilig, C. Bourauel, A. Jäger. Corrosion susceptibility and nickel release of nickel titanium wires during clinical application. J Orofac Orthop, 69 (2008), pp. 411-423

6 J. Daems, J.P. Celis, G. Willems. Morphological characterization of as-received and in vivo orthodontic stainless steel archwires. Eur J Orthod, 31 (2009), pp. 260-265

7 T.H. Huang, C.C. Yen, C.T. Kao. Comparison of ion release from new and recycled orthodontic brackets. Am J Orthod Dentofacial Orthop, 120 (2001), pp. 68-75

8 H.Y. Park, T.R. Shearer. In vitro release of nickel and chromium from simulated orthodontic appliances. Am J Orthod, 84 (1983), pp. 156-159

9 S.E. Bishara, R.D. Barrett, M.I. Selim. Biodegradation of orthodontic appliances. Part II. Changes in the blood level of nickel. Am J Orthod Dentofacial Orthop, 103 (1993), pp. 115-119

10 T. Eliades, H. Pratsinis, D. Kletsas, G. Eliades, M. Makou. Characterization and cytotoxicity of ions released from stainless steel and nickel-titanium orthodontic alloys. Am J Orthod Dentofacial Orthop, 125 (2004), pp. 24-29

11 H.H. Huang, Y.H. Chiu, T.H. Lee, S.C. Wu, H.W. Yang, K.H. Su, et al. Ion release from NiTi orthodontic wires in artificial saliva with various acidities. Biomaterials, 24 (2003), pp. 3585-3592

12 N.K. Sarkar, W. Redmond, B. Schwaninger, A.J. Goldberg. The chloride corrosion behaviour of four orthodontic wires. J Oral Rehabil, 10 (1983), pp. 121-128

13 J.S. Shin, K.T. Oh, C.J. Hwang. In vitro surface corrosion of stainless steel and NiTi orthodontic appliances. Aust Orthod J, 19 (2003), pp. 13-18

14 Y. Yonekura, K. Endo, M. lijima, H. Ohno, I. Mizoguchi. In vitro corrosion characteristics of commercially available orthodontic wires. Dent Mater J, 23 (2004), pp. 197-202

$15 \mathrm{H} . \mathrm{H}$. Huang. Variation in corrosion resistance of nickel-titanium wires from different manufacturers. Angle Orthod, 75 (2005), pp. 661-665

16 J.A. Platt, A. Guzman, A. Zuccari, D.W. Thornburg, B.F. Rhodes, Y. Oshida, et al. Corrosion behavior of 2205 duplex stainless steel. Am J Orthod Dentofacial Orthop, 112 (1997), pp. 69-79

17 M. lijima, K. Endo, T. Yuasa, H. Ohno, K. Hayashi, M. Kakizaki, et al. Galvanic corrosion behavior of orthodontic archwire alloys coupled to bracket alloys. Angle Orthod, 76 (2006), pp. 705-711

18 B. Siargos, T.G. Bradley, M. Darabara, G. Papadimitriou, S. Zinelis. Galvanic corrosion of metal injection molded (MIM) and conventional brackets with nickel-titanium and copper-nickel-titanium archwires. Angle Orthod, 77 (2007), pp. 355-360

19 M.S. Darabara, L.I. Bourithis, S. Zinelis, G.D. Papadimitriou. Metallurgical characterization, galvanic corrosion, and ionic release of orthodontic brackets coupled with Ni-Ti archwires. $J$ Biomed Mater Res B Appl Biomater, 81 (2007), pp. 126-134

20 N. Schiff, M. Boinet, L. Morgon, M. Lissac, F. Dalard, B. Grosgogeat. Galvanic corrosion between orthodontic wires and brackets in fluoride mouthwashes. Eur J Orthod, 28 (2006), pp. 298-304

21 J.C. Wataha. Biocompatibility of dental casting alloys: a review. J Prosthet Dent, 83 (2000), pp. 223-234

22 M.C. Genelhu, M. Marigo, L.F. Alves-Oliveira, L.C. Malaquias, R.S. Gomez. Characterization of nickel-induced allergic contact stomatitis associated with fixed orthodontic appliances. Am J Orthod Dentofacial Orthop, 128 (2005), pp. 378-381

23 O.E. Kolokitha, E.G. Kaklamanos, M.A. Papadopoulos. Prevalence of nickel hypersensitivity in orthodontic patients: a meta-analysis. Am J Orthod Dentofacial Orthop, 134 (2008)722.e1-12

24 R.P. Kusy. Clinical response to allergies in patients. Am J Orthod Dentofacial Orthop, 125 (2004), pp. 544-547

25 K. House, F. Sernetz, D. Dymock, J.R. Sandy, A.J. Ireland. Corrosion of orthodontic appliances-should we care? Am J Orthod Dentofacial Orthop, 133 (2008), pp. 584-592

26 C. Bourauel, T. Fries, D. Drescher, R. Plietsch. Surface roughness of orthodontic wires via atomic force microscopy, laser specular reflectance, and profilometry. Eur J Orthod, 20 (1998), pp. 79-92

27 D.K. Pun, D.W. Berzins. Corrosion behavior of shape memory, superelastic, and nonsuperelastic nickeltitanium-based orthodontic wires at various temperatures. Dent Mater, 24 (2008), pp. 221-227

28 R.S. Walker, A.G. Wade, G. lazzetti, N.K. Sarkar. Galvanic interaction between gold and amalgam. J Am Dent Assoc, 134 (2003), pp. 1463-1467 
29 W.A. Brantley, T. Eliades. Orthodontic materials: scientific and clinical aspects. Thieme, Stuttgart, Germany (2001)

30 J.D. Wing. Metallographic structure and composition of two titanium and two stainless steel orthodontic brackets [thesis]. Marquette University, Milwaukee, Wis (2004)

31 M.G. Fontana. Corrosion engineering. (3rd ed.), McGraw-Hill, New York (1986)

$32 \mathrm{~S}$. Zinelis, O. Annousaki, M. Makou, T. Eliades. Metallurgical characterization of orthodontic brackets produced by metal injection molding (MIM). Angle Orthod, 75 (2005), pp. 1024-1031

33 Safety data sheets. Ispringen, Germany: Dentaurum. Available at: http://www.dentaurum.de. Accessed on October 4, 2005.

34 C. Gioka, C. Bourauel, S. Zinelis, T. Eliades, N. Silikas, G. Eliades. Titanium orthodontic brackets: structure, composition, hardness and ionic release. Dent Mater, 20 (2004), pp. 693-700

35 E. Petoumenou, M. Arndt, L. Keilig, S. Reimann, H. Hoederath, T. Eliades, et al. Nickel concentration in the saliva of patients with nickel-titanium orthodontic appliances. Am J Orthod Dentofacial Orthop, 135 (2009), pp. 59-65

36 T. Eliades, A.E. Athanasiou. In vivo aging of orthodontic alloys: implications for corrosion potential, nickel release, and biocompatibility. Angle Orthod, 72 (2002), pp. 222-237 